\title{
AUXILIARY POWER UNIT CONTROL FOR HYBRID ELECTRIC VEHICLES
}

\author{
G. Fiengo $(*)$, C. Di Fiore $\left({ }^{\circ}\right)$, D. Lepore $\left({ }^{\circ}\right)$, F. Vasca $(*)$ \\ (*)Dipartimento di Ingegneria, Università del Sannio, Corso Garibaldi 107, 82100 Benevento, Italy \\ Tel. +390824 305585 - 5570, Fax. +390824 30 5840, Email: \{gifiengo, vasca\}@ unisannio.it \\ $\left(^{\circ}\right)$ Centro Ricerche FIAT, Pomigliano, Napoli, Italy.
}

Keywords: Automotive control, hybrid electric vehicles, induction motor control, internal combustion engine, battery management.

\begin{abstract}
The control of a typical Auxiliary Power Unit for series type hybrid electric vehicles is considered. The APU is equipped with an internal combustion engine and with an electrical induction motor used as starting motor and as battery charging generator. Dynamic models of both engine and motor are considered and exploited for the design of the APU controller. A field oriented control scheme and a decoupling controller with two independent current control loops is used for the motor whereas a torque controller regulates the engine transients. The control of the whole APU is thus designed by coupling the engine and motor controllers through a cascaded feedback control approach. Different APU control strategies are used depending on the shaft speed and on the power requested by the battery management system. Simulation results are carried out with Matlab/Simulink. Small oscillations in the battery charging current and small power tracking error confirm the effectiveness of the proposed controller both in steady state and during transients.
\end{abstract}

\section{Introduction}

Hybrid vehicles are becoming more and more near to a large scale industrial production. On the other hand, several problems related to their configurations and to the expected performances are still under investigation. Among others the control of the system devoted to battery charging is one of the most interesting problem. In this framework, a possible solution in series hybrid vehicle is to use a so called Auxiliary Power Unit (APU). In this paper we propose a new control strategy for an APU whose main elements are:

- a reversible voltage source DC-AC power converter, called inverter in the sequel;

- a three-phase induction Electric Motor (EM);

- a two cylinders Internal Combustion Engine (ICE);

- an APU control unit;

- a motorized throttle valve for the management of the air mass charge in the ICE.

The ICE is physically connected to the EM trough a common shaft. The EM operates as a motor during the start-up phase and as a generator when the ICE is switched-on, thus providing the requested charging current to the battery. An external supervisor drives the APU with a power or current request. The strategies used by the supervisor in order to provide this demand depend on the specific APU operating conditions which can be classified into the following phases: start-up, warm-up, low power generation, high power generation, switching off. Different control strategies depending on the specific operating phase are proposed, pointing out the effort of the controller to minimize the oscillations in the current charging the battery due to the pulsating ICE torque.

The paper is organised as follows. In Section 2 the models of the electric motor [1] and of the internal combustion engine [7]-[8] are introduced. Then in Section 3 the proposed control strategies are presented and in Section 4 simulation results based on Matlab/Simulink/Stateflow platform are presented showing the effectiveness of the proposed control strategies.

\section{Dynamic models}

\subsection{Induction Motor/Generator}

By choosing as state variables the stator currents $i_{D}, i_{Q}$ and the rotor fluxes $\phi_{d}, \phi_{q}$ (the state equation corresponding to the rotor speed $\omega_{r}$, will be determined by the coupling of motor and engine) the EM dynamic model can be written as follows:

$$
\begin{aligned}
\frac{\mathrm{di}_{\mathrm{D}}}{\mathrm{dt}}=-\frac{\mathrm{R}_{\mathrm{sr}}}{\sigma \mathrm{L}_{\mathrm{s}}} \mathrm{i}_{\mathrm{D}}+\frac{\mathrm{R}_{\mathrm{r}} \mathrm{M}}{\sigma \mathrm{L}_{\mathrm{s}} \mathrm{L}_{\mathrm{r}}{ }^{2}} \varphi_{\mathrm{d}}+\frac{\mathrm{M}}{\sigma \mathrm{L}_{\mathrm{s}} \mathrm{L}_{\mathrm{r}}} \omega_{\mathrm{r}} \varphi_{\mathrm{q}}+\frac{1}{\sigma \mathrm{L}_{\mathrm{s}}} \mathrm{v}_{\mathrm{D}} \\
\frac{\mathrm{di}_{\mathrm{Q}}}{\mathrm{dt}}=-\frac{\mathrm{R}_{\mathrm{sr}}}{\sigma \mathrm{L}_{\mathrm{s}}} \mathrm{i}_{\mathrm{Q}}-\frac{\mathrm{M}}{\sigma \mathrm{L}_{\mathrm{s}} \mathrm{L}_{\mathrm{r}}} \omega_{\mathrm{r}} \phi_{\mathrm{d}}+\frac{\mathrm{R}_{\mathrm{r}} \mathrm{M}}{\sigma \mathrm{L}_{\mathrm{s}} \mathrm{L}_{\mathrm{r}}{ }^{2}} \phi_{\mathrm{q}}+\frac{1}{\sigma \mathrm{L}_{\mathrm{s}}} \mathrm{v}_{\mathrm{Q}} \\
\frac{\mathrm{d} \phi_{\mathrm{d}}}{\mathrm{dt}}=\frac{\mathrm{MR}_{\mathrm{r}} \mathrm{i}_{\mathrm{D}}-\frac{\mathrm{R}_{\mathrm{r}}}{\mathrm{L}_{\mathrm{r}}} \phi_{\mathrm{d}}-\omega_{\mathrm{r}} \phi_{\mathrm{q}}}{\frac{\mathrm{d} \phi_{\mathrm{q}}}{\mathrm{dt}}}=\frac{\mathrm{MR}_{\mathrm{r}} \mathrm{i}_{\mathrm{Q}}+\omega_{\mathrm{r}} \phi_{\mathrm{d}}-\frac{\mathrm{R}_{\mathrm{r}}}{\mathrm{L}_{\mathrm{r}}} \phi_{\mathrm{q}}}{\mathrm{T}_{\mathrm{r}}}=\frac{3}{2} \frac{\mathrm{N}_{\mathrm{cp}} \mathrm{M}}{\mathrm{L}_{\mathrm{r}}}\left(\phi_{\mathrm{d}} \mathrm{i}_{\mathrm{Q}}-\phi_{\mathrm{q}} \mathrm{i}_{\mathrm{D}}\right)
\end{aligned}
$$

where $v_{D}, v_{Q}$ are the stator voltages, $T_{L}$ is a load torque, $\sigma=1-$ $M^{2} /\left(L_{s} L_{r}\right)$, and $R_{s r}=R_{s}+R_{r} M^{2} / L_{r}^{2}$. The induction motor parameters are: $N_{c p}=3, R_{s}=0.0392 \Omega, R_{r}=0.0216 \Omega, L_{l s}=$ $0.2241 \mathrm{mH}, L_{l r}=0.2020 \mathrm{mH}, M=3.3568 \mathrm{mH}, L_{s}=L_{l s}+M$, $L_{r}=L_{l r}+M$. The dynamic model (1)-(5) can be also rewritten in a generic reference frame rotating at speed $\omega_{a x}$. In particular if a frame synchronous with the rotor flux is chosen (prime is used to indicate the variables in this reference frame) the model (1)-(5) can be rewritten as 


$$
\begin{gathered}
\frac{\mathrm{di}_{\mathrm{D}}^{\prime}}{\mathrm{dt}}=-\frac{\mathrm{R}_{\mathrm{sr}}}{\sigma \mathrm{L}_{\mathrm{s}}} \mathrm{i}_{\mathrm{D}}^{\prime}+\omega \mathrm{i}_{\mathrm{D}}^{\prime}+\frac{\mathrm{R}_{\mathrm{r}} \mathrm{M}}{\sigma \mathrm{L}_{\mathrm{s}} \mathrm{L}_{\mathrm{r}}{ }^{2}} \phi_{\mathrm{d}}^{\prime}+\frac{1}{\sigma \mathrm{L}_{\mathrm{s}}} \mathrm{v}_{\mathrm{D}}^{\prime} \\
\frac{\mathrm{di}_{\mathrm{Q}}^{\prime}}{\mathrm{dt}}=-\omega \mathrm{i}_{\mathrm{D}}^{\prime}-\frac{\mathrm{R}_{\mathrm{sr}}}{\sigma \mathrm{L}_{\mathrm{s}}} \mathrm{i}_{\mathrm{Q}}^{\prime}-\frac{\mathrm{M}}{\sigma \mathrm{L}_{\mathrm{s}} \mathrm{L}_{\mathrm{r}}} \omega_{\mathrm{r}} \phi_{\mathrm{d}}^{\prime}+\frac{1}{\sigma \mathrm{L}_{\mathrm{s}}} \mathrm{v}_{\mathrm{Q}}^{\prime} \\
\frac{\mathrm{d} \phi_{\mathrm{d}}^{\prime}}{\mathrm{dt}}=\frac{\mathrm{MR}_{\mathrm{r}}}{\mathrm{L}_{\mathrm{r}}} \mathrm{i}_{\mathrm{D}}^{\prime}-\frac{\mathrm{R}_{\mathrm{r}}}{\mathrm{L}_{\mathrm{r}}} \phi_{\mathrm{d}}^{\prime} \\
0=\frac{M R_{\mathrm{r}}}{\mathrm{L}_{\mathrm{r}}} \mathrm{i}_{\mathrm{Q}}^{\prime}-\left(\omega-\omega_{\mathrm{r}}\right) \phi_{\mathrm{d}}^{\prime} \\
\mathrm{T}_{\mathrm{em}}=\frac{3}{2} \frac{\mathrm{N}_{\mathrm{cp}} \mathrm{M}}{\mathrm{L}_{\mathrm{r}}}\left(\phi_{\mathrm{d}}^{\prime} \mathrm{i}_{\mathrm{Q}}^{\prime}\right)
\end{gathered}
$$

The model (6)-(10) will be used for the current control design.

\subsection{Internal Combustion Engine}

In order to simulate the ICE, a physics model is developed. Based on the throttle angle, the model simulates the dynamics of the air/fuel mixture across the intake manifold, the combustion process occurring in the cylinders and finally the dynamics of the burned gases in the exhaust manifold. The output is the torque generated by the combustion. For sake of brevity, the dynamics of the gases across the intake and exhaust manifold (see [6] and [7]) are omitted while the combustion process is briefly described (see [3]).

The model predicts the engine torque by using the cylinder pressure throughout the intake, compression, combustion, expansion and exhaust processes of the engine operating cycle. Pressure was modelled as a function of the angle of the crank. The valve and spark timings, engine geometry, engine speed and inlet pressure enter into the model. In the following, each process of the engine operating cycle are discussed in order to highlight how the corresponding pressure is determined.

\section{A. Intake.}

Intake occurs between exhaust valve closing and the start of compression. The intake valve opens while the exhaust valve is still opened (period of overlap during which both valves are open) and closes after bottom centre. The engine speed determines the point at which the fuel/air mixture stops flowing into the cylinder. The volume of the cylinder during intake increases drawing in the air/fuel mixture. The pressure in the cylinder remains relatively constant and equal to the inlet pressure due to a small resistance that the gas encounters flowing into the cylinder.

\section{B. Compression.}

Both the intake and exhaust valves are closed during the compression phase. The piston is moving upward, so cylinder volume decreases. Pressure increases as the gas in the cylinder is compressed. Because of the high speed of the piston, the duration of compression is short and negligible heat is lost to the walls of the cylinder. A relatively little amount of energy is also dissipated due to internal friction of the gas. Overall, there is little change in entropy during compression, and the gas behaviour can be described by the equation:

$$
\mathrm{pV}^{\gamma}=\text { const }
$$

where $\gamma$ is the ratio of the specific heat of the fuel at constant pressure and at constant volume. Its value depends on the engine phase and during compression is approximately equal to 1.3. This equation calculates the cylinder pressure at any crank angle during compression, based on the knowledge of initial pressure and volume, $\mathrm{P}_{0}$ and $\mathrm{V}_{0}$. The volume of the cylinder is function of crank angle, cylinder geometries, crank radius and connecting rod length.

\section{Combustion.}

The combustion process was described in according to the ideal gas law: the gas pressure at the end of combustion is a function of the mass of the gases, temperature, and volume.

$$
\mathrm{p}_{\text {end_comb }}=\frac{\mathrm{p}_{\text {start_compr }}}{\mathrm{T}_{\text {start_compr }}} \rho \frac{\sum \mathrm{n}_{\mathrm{i}_{-} \text {end_comb }}}{\sum \mathrm{n}_{\mathrm{i}_{-} \text {end_compr }}} \mathrm{T}_{\text {end_comb }}
$$

where:

$\mathrm{n}_{\mathrm{i} \_ \text {end_comb }}=$ number of gas moles after combustion

$\mathrm{n}_{\mathrm{i} \_ \text {end_compr }}=$ number of gas moles before compression

$\rho=$ volumetric ratio

$\mathrm{p}_{\mathrm{x}}=$ pression in cylinder

$\mathrm{T}_{\mathrm{x}}=$ temperature in cylinder

\section{Expansion.}

The end of combustion occurs slightly after top centre and at the same time expansion begins. The pressure of the burned gases drives the piston down, providing power to the car. Similarly to the compression phase, the gas behaviour was described by equation (11).

The combustion process releases gases and increases the temperature within the space. The expansion of gases forces the piston to move. The movement is transmitted through specially designed parts to a shaft. The resulting rotary motion of the shaft is used for work.

\section{E. Blowdown and Exhaust.}

Exhaust valve opening occurs before the crank reaches the bottom centre. At this point, the pressure in the cylinder is much greater than the exhaust system pressure. The higher pressure in the cylinder helps to push the burned gases out of the cylinder. This process is called blowdown. The flow of the gases can be described by a model of gas flow through an orifice where the valve acts like the flow restriction. This model depends on the velocity of the gas: when the gas velocity at the smallest portion of the opening, the throat, is equal to the speed of sound, the flow is said to be choked. Intake, blowdown valves and air bypass are describes by following equations:

$$
\left\{\begin{array}{l}
1 \boldsymbol{\alpha}_{\text {choked }}=\frac{\mathrm{C}_{\mathrm{D}} \mathrm{A}_{\mathrm{T}} \mathrm{p}_{\mathrm{o}}}{\sqrt{\mathrm{RT}_{\mathrm{o}}}} \gamma^{1 / 2}\left(\frac{2}{\gamma+1}\right)^{(\gamma+1) / 2(\gamma-1)} \\
1 \boldsymbol{\alpha}_{\text {not_choked }}=\frac{\mathrm{C}_{\mathrm{D}} \mathrm{A}_{\mathrm{T}} \mathrm{p}_{\mathrm{o}}}{\sqrt{\mathrm{RT}_{\mathrm{o}}}}\left(\frac{\mathrm{p}_{\mathrm{T}}}{\mathrm{p}_{\mathrm{o}}}\right)^{1 / \gamma}\left\{\frac{2 \gamma}{\gamma-1}\left[1-\left(\frac{\mathrm{p}_{\mathrm{T}}}{\mathrm{p}_{\mathrm{o}}}\right)^{(\gamma-1) / \gamma}\right]\right\}^{1 / 2}
\end{array}\right.
$$

where:

- $\hat{\mathrm{f}}_{\text {choked }}$ mass flow rate in sonic flow condition; 
- $\mathfrak{f}_{\text {not }}$ choked mass flow rate in not sonic flow condition;

- $\mathrm{p}_{\mathrm{a}} \quad$ air pression before orifice;

- $\mathrm{p}_{\mathrm{T}} \quad$ air pression after orifice;

- $\mathrm{T}_{\mathrm{o}}$ gas temperature;

- $\mathrm{C}_{\mathrm{D}} \quad$ lost coefficient;

- $\mathrm{A}_{\mathrm{T}} \quad$ flow section;

- $\gamma \quad$ ratio of specific heats $\mathrm{c}_{\mathrm{p}} / \mathrm{c}_{\mathrm{v}}$;

- $\mathrm{R}$ gas constant.

\section{F. Engine torque}

Once obtained the cylinder pressure for each phase of the combustion, is possible to compute the torque generated (see [4] and [5]) according to:

$$
\mathrm{T}_{\mathrm{i}}=\frac{\pi \mathrm{D}_{\mathrm{m}}^{2} \mathrm{C}_{\mathrm{m}}}{8}\left(\mathrm{p}_{\mathrm{i}}-\mathrm{p}_{\mathrm{b}}\right) \operatorname{sen} \theta\left(1+\frac{\cos \theta}{\sqrt{\mu^{2}-\operatorname{sen}^{2} \theta}}\right)
$$

where (see figure 1)

- $\mathrm{T}$ engine torque;

- $\mathrm{p}_{\mathrm{i}}$ engine gas pressure into cylinder;

- $\theta$ crankshaft angle;

- $\mathrm{p}_{\mathrm{b}}$ base pressure (it is equal to the atmosferic pressure);

- $\mathrm{D}_{\mathrm{m}}$ bore cylinder;

- $\mathrm{C}_{\mathrm{m}}$ piston stroke;

- $\mu$ connecting-rod ratio $\left(L / r=2 L / C_{m}\right)$

The total torque generated by the ICE is the sum of the torque generated by each cylinder (eq. (14)):

$$
\mathrm{T}_{\mathrm{ICE}}=\sum_{i=1}^{2} T_{i}
$$

\subsection{APU Shaft Model}

The mechanical equation corresponding to the APU shaft speed can be determined by considering that the EM and the ICE are mounted on the same shaft and therefore the sum of the corresponding torques determines the shaft rotation:

$$
\mathrm{J} \frac{\mathrm{d} \omega_{\mathrm{r}}}{\mathrm{dt}}=-\mathrm{B} \omega_{\mathrm{r}}+\mathrm{N}_{\mathrm{cp}}\left(\mathrm{T}_{\mathrm{em}}+\mathrm{T}_{\mathrm{ICE}}-\mathrm{T}_{\mathrm{scoll}}\right)
$$

where $T_{\text {ICE }}$ is the torque generated by the ICE, $T_{\mathrm{em}}$ is the torque of the EM and $\mathrm{T}_{\text {scoll }}$ is the friction torque acting only when the engine is starting up.

\section{Controller design}

\subsection{Controller objectives}

The main objective of the APU is to provide to the battery the desired power as fast as possible and without undesired overshoot and oscillations in the charging current. Different APU operating conditions are considered.

- Start-up. The EM drives the engine up to a shaft speed of $2000 \mathrm{rpm}$ with a maximum speed acceleration of $1000 \mathrm{rpm} / \mathrm{s}$. The motor torque at zero speed must be larger than the static friction torque $\mathrm{T}_{\text {scoll }}$ (see (16)) which is assumed to be $16 \mathrm{Nm}$.

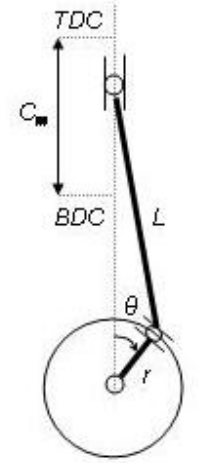

Figure 1: cylinder and crankshaft scheme

- Warm-up. When the ICE is cold, the EM regulates the shaft speed at $2000 \mathrm{rpm}$ and the ICE generates a minimum amount of power (corresponding to 2 bar of PME). This is aimed to optimize the warming up of the engine and the catalyst, thus reducing the pollutant emissions. The warm up phase is regulated by considering the cooling water temperature. If this temperature is larger than $25^{\circ} \mathrm{C}$ the APU can start to furnish power to the battery and the warm-up phase is concluded.

- Low-power generation. In order to generate power, the EM will start operating as a generator charging the battery through the inverter. To optimize the fuel consumption, emissions and damaging, the power charging the battery is generated at a constant speed of $2000 \mathrm{rpm}$, by increasing the ICE torque. If the power requested by the battery management system is greater than the maximum power which can be generated at that speed $(6 \mathrm{~kW})$, a new APU phase will start.

- High-power generation. In this phase the ICE torque is obtained form the characteristic curve corresponding to $80 \%$ of the maximum torque and the power is increased by increasing the speed (i.e. reducing the load torque provided by the EM).

- Transient functioning. The transients are managed acting at the same time on the internal combustion engine and the electric motor.

- Switching off. The ICE is switched off and the EM regulates the shaft speed to zero with a maximum deceleration equal to $1000 \mathrm{rpm} / \mathrm{s}$. When the APU must be switched off it is important to maintain the engine on until the water cooling temperature is decreased to safety values, in order to avoid the heat exhaustion due to the early deactivation of the cooling system.

The following quantitative constraints have been considered as the task of the APU control. The speed range is between $2000 \mathrm{rpm}$ and $4500 \mathrm{rpm}$; the corresponding power request is between $1 \mathrm{~kW}$ and $15 \mathrm{~kW}$ with a nominal battery voltage equal to $312 \mathrm{~V}$, a minimum battery voltage equal to $260 \mathrm{~V}$ and a maximum value equal to $400 \mathrm{~V}$. The average battery current thus can vary between $3 \mathrm{~A}$ (if at $1 \mathrm{~kW}$ ) and $45 \mathrm{~A}$ (if at $15 \mathrm{~kW}$ ). At $2000 \mathrm{rpm}$ the speed oscillations must be between $\pm 75 \mathrm{rpm}$ and the current oscillations between $\pm 1.5 \mathrm{~A}$. At larger power the oscillations constraints can be relaxed; for 
instance at $10 \mathrm{~kW}$, the speed can be $4500 \pm 70 \mathrm{rpm}$, and the battery current $29 \pm 3 \mathrm{~A}$.

\subsection{APU control scheme}

Different APU control strategies are used depending on the operating conditions. During start-up the electric motor drives the engine up to $2000 \mathrm{rpm}$. In this phase the EM is controlled through a PI feedback loop on the shaft speed. The same controller is also used when the APU must be switched off. When the engine is started and the APU starts operating in the low-power generation phase, a different control strategy is adopted. Since the electrical dynamics are faster than the engine dynamics, we have proposed a speed control for the engine and a torque control for the generator. The control scheme corresponding to these operating conditions is reported in Figure 2. In the outline three main parts can be distinguished:

- a block that transforms the demanded power $\left(\mathrm{P}_{\text {rif }}\right)$ into a reference torque $\left(\mathrm{T}_{\text {rif }}\right)$ and a reference speed $\left(\omega_{\text {rif }}\right)$;

- a cascade controller for the ICE that regulates the engine speed;

- a torque controller for the EM.

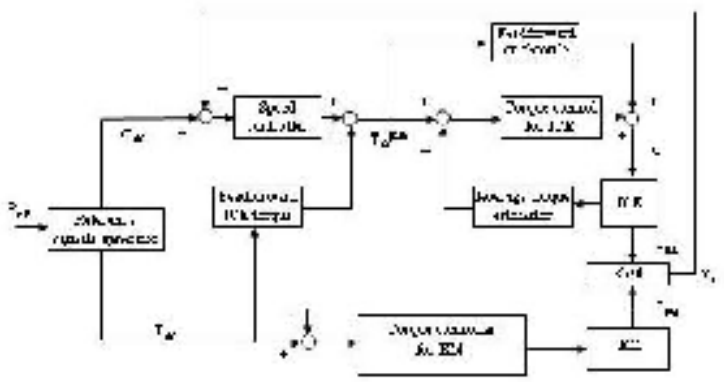

Figure 2: APU control scheme.

\section{A. Reference signals generator}

If the APU operates in the low-power generation phase the speed reference is $\omega_{\text {rif }}=2000 \mathrm{rpm}$, while, since in order to obtain the desired power generation, the torque reference for the $\mathrm{EM}$ is equal to

$$
\mathrm{T}_{\text {rif }}=\frac{\mathrm{P}_{\text {rif }}}{\omega_{\text {rif }}}
$$

One of the main problems in the management of the APU is given by the oscillations in the torque generated by the ICE. These oscillations are propagated on the engine shaft speed and therefore on the current charging the batteries. Then, if we wish that the battery current does not oscillate, since the power on the battery is $\mathrm{P}=\mathrm{V}_{\mathrm{b}} \mathrm{I}_{\mathrm{b}} \cong \mathrm{T}_{\mathrm{EM}} \cdot \omega_{\mathrm{r}}$ and the shaft speed oscillates, we need that the oscillations on the EM torque and on the shaft speed are such that they compensates thus generating an almost constant power (and, consequently, almost constant battery current). To this aim, the torque reference for the EM has been replaced with:

$$
\mathrm{T}_{\text {rif }}=\frac{\mathrm{P}_{\text {rif }}}{\omega_{\text {rif }}} \frac{\omega_{\mathrm{av}}}{\omega_{\mathrm{r}}}
$$

where $\omega_{\mathrm{av}}$ is the mean value of the shaft speed and $\omega_{\mathrm{r}}$ is the real one.
If the APU operates in the high-power phase (i.e. the demanded power is greater of $6 \mathrm{~kW}$ ), the reference signals are obtained by using the static curves of torque and power at the $80 \%$ of their maximum values, $\mathrm{T}_{80 \%}(\omega)$ and $\mathrm{P}_{80 \%}(\omega)$. In particular, from the demanded value of power the corresponding reference speed is obtained by inverting the power static curve; the reference torque is determined by means of the torque static curve using the average shaft speed $\left(\omega_{\mathrm{av}}\right)$. Finally, the value of reference torque obtained is modified, so as in (18), multiplying by $\omega_{\mathrm{av}}$ and dividing by $\omega_{\mathrm{r}}$, in order to reduce the oscillations in the battery current.

\section{B. Internal combustion engine control}

The internal combustion engine is controlled with two regulators in cascade (see Figure 2) with a faster inner cycle for the torque control and a slower external cycle for the speed control. The external controller regulates the shaft speed, comparing the reference signal with the average speed. The controller is a simple PI whose parameters assume different values depending on the generated power. The output of the speed regulator is added to a feed-forward action, equal to the mean value of the torque reference for the EM (in steady state, i.e. constant speed, the two torques must be equal). In such way a reference value $\left(\mathrm{T}_{\text {rif }}{ }^{\mathrm{ICE}}\right)$ for the inner control cycle is obtained.

The inner controller feeds back an estimation of the average torque generated by the engine and commands the opening of the throttle valve $(\alpha)$. This controller is formed by a PI regulator and a feed-forward action. The PI output is limited between $-5^{\circ}$ and $5^{\circ}$ of opening of the throttle valve and thus is also equipped with an anti-windup strategy. The feed-forward action is obtained with a static table that calculates the steady state value of the angle of opening of the throttle valve as function of the average shaft speed and the desired torque.

\section{Induction motor control}

The EM control scheme we propose (see [1]) is reported in Figure 3. The "Speed Controller" is used only during start-up, warm-up and switching-off phase, whereas during the power generation phases the input of the EM control is directly the reference torque by passing the speed controller (see Figure 2). The "Torque-Current" block converts the reference torque in a reference value for the current component $i_{Q}^{\prime}$. The "Current Controller" block allows the decoupled regulation of the current components $i_{D}^{\prime}$ and $i_{Q}^{\prime}$ to their reference values. The "Rotation" block implements the variable transformation from a synchronous reference frame to fixed one.

Equation (8) shows that, by considering the stator current $i_{D}^{\prime}$ as an input and the rotor flux $\phi_{d}$ ' as an output, the corresponding transfer function is given by a simple first order system. This model can be used to design the "Flux Controller" which can be chosen as a simple PI controller with transfer function $k_{p}+k_{i} / s$, where $k_{p}$ and $k_{i}$ must be suitably chosen, e.g. by ensuring a closed loop system faster than the open loop one.

Since the stator currents must be upper bounded, a saturation on the controller output is considered. In particular, it is assumed that the maximum current reference is $30 \%$ larger 
than the nominal current. As it is well known, due to the presence of the saturation and the integral controller action, the performance of the closed loop system can drastically deteriorate. In order to overcome this drawback an anti-windup scheme is implemented. Note that in the actual scheme the rotor flux component $\phi_{d}$ ' will be replaced by its estimate.

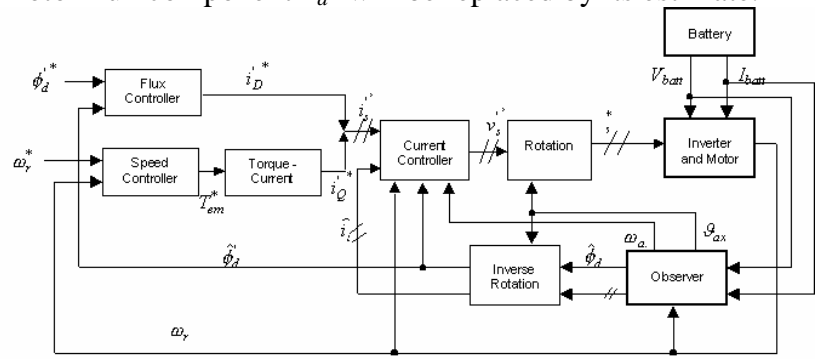

Figure 3: General control scheme of the induction motor.

So as shown in Figure 3, the outputs of the torque and flux regulators are the current references which become the inputs for the "Current Controller". This controller must generate the stator voltages $v_{D}^{\prime}$ and $v_{Q}^{\prime}$ which are inputs for the motor. In order to design the current controller we consider (6) and (7). By introducing the new variables

$$
\begin{aligned}
& u_{D}^{\prime}=v_{D}^{\prime}+\frac{R_{r} M}{L_{r}^{2}} \phi_{d}^{\prime} \\
& u_{Q}^{\prime}=v_{Q}^{\prime}-\frac{M}{L_{r}} \omega_{r} \phi_{d}^{\prime}
\end{aligned}
$$

equations (6)-(7) become:

$$
\begin{aligned}
& \frac{\mathrm{d}}{\mathrm{dt}} \mathrm{i}_{\mathrm{D}}^{\prime}=-\frac{\mathrm{R}_{\mathrm{sr}}}{\sigma \mathrm{L}_{\mathrm{s}}} \mathrm{i}_{\mathrm{D}}^{\prime}+\omega_{\mathrm{ax}} \mathrm{i}_{\mathrm{Q}}^{\prime}+\frac{1}{\sigma \mathrm{L}_{\mathrm{s}}} \mathrm{u}_{\mathrm{D}}^{\prime} \\
& \frac{\mathrm{d}}{\mathrm{dt}} \mathrm{i}_{\mathrm{Q}}^{\prime}=-\omega_{\mathrm{ax}} \mathrm{i}_{\mathrm{D}}^{\prime}-\frac{\mathrm{R}_{\mathrm{sr}}}{\sigma \mathrm{L}_{\mathrm{s}}} \mathrm{i}_{\mathrm{Q}}^{\prime}+\frac{1}{\sigma \mathrm{L}_{\mathrm{s}}} \mathrm{u}_{\mathrm{Q}}^{\prime}
\end{aligned}
$$

that correspond to a two-inputs $\left(u_{D}^{\prime}\right.$ and $\left.u_{Q}^{\prime}\right)$ two-outputs $\left(i_{D}^{\prime}\right.$ and $\mathrm{i}_{\mathrm{Q}}^{\prime}$ ) system. By assuming $\omega_{a x}$ to be constant and by computing the transfer functions corresponding to (21)-(22), one can design a decoupling controller that allows to regulate the current $i_{D}^{\prime}$ independently from the current $i_{Q}^{\prime}$ [2]. In particular, by applying the Laplace transform to (21)-(22) one obtains

$$
\left(\begin{array}{l}
I_{D}^{\prime}(s) \\
I_{Q}^{\prime}(s)
\end{array}\right)=\frac{1 /\left(\sigma L_{s}\right)}{\left(s+\frac{R_{s r}}{\sigma L_{s}}\right)^{2}+\omega_{a x}^{2}}\left(\begin{array}{cc}
s+\frac{R_{s r}}{\sigma L_{s}} & \omega_{a x} \\
-\omega_{a x} & s+\frac{R_{s r}}{\sigma L_{s}}
\end{array}\right)\left(\begin{array}{c}
U_{D}^{\prime}(s) \\
U_{Q}^{\prime}(s)
\end{array}\right)
$$

By defining

$$
\left(\begin{array}{c}
U_{D}^{\prime}(s) \\
U_{Q}^{\prime}(s)
\end{array}\right)=\left(\begin{array}{cc}
1 & -D(s) \\
-D(s) & 1
\end{array}\right)\left(\begin{array}{l}
U_{D}^{\prime \prime}(s) \\
U_{Q}^{\prime \prime}(s)
\end{array}\right)
$$

with

$$
\mathrm{D}(\mathrm{s})=\frac{1}{\mathrm{~s}+\frac{\mathrm{R}_{\mathrm{sr}}}{\sigma \mathrm{L}_{\mathrm{s}}}} \omega_{\mathrm{ax}}
$$

substituting (24) in (23) yields

$$
\left.\left(\begin{array}{l}
\mathrm{I}_{\mathrm{D}}^{\prime}(\mathrm{s}) \\
\mathrm{I}_{\mathrm{Q}}^{\prime}(\mathrm{s})
\end{array}\right)=\frac{1}{\sigma \mathrm{L}_{\mathrm{s}}\left(\mathrm{s}+\frac{\mathrm{R}_{\mathrm{sr}}}{\sigma \mathrm{L}_{\mathrm{s}}}\right.}\right)\left(\begin{array}{ll}
1 & 0 \\
0 & 1
\end{array}\right)\left(\begin{array}{c}
\mathrm{U}_{\mathrm{D}}^{\prime \prime}(\mathrm{s}) \\
\mathrm{U}_{\mathrm{Q}}^{\prime \prime}(\mathrm{s})
\end{array}\right)
$$

which is a two-input two-output system completely decoupled. From (26) it is simple to obtain the following time domain representation of the two subsystems:

$$
\begin{aligned}
& \frac{\mathrm{d}}{\mathrm{dt}} \mathrm{i}_{\mathrm{D}}^{\prime}=-\frac{\mathrm{R}_{\mathrm{sr}}}{\sigma \mathrm{L}_{\mathrm{s}}} \mathrm{i}_{\mathrm{D}}^{\prime}+\frac{1}{\sigma \mathrm{L}_{\mathrm{s}}} \mathrm{u}_{\mathrm{D}}^{\prime \prime} \\
& \frac{\mathrm{d}}{\mathrm{dt}} \mathrm{i}_{\mathrm{Q}}^{\prime}=-\frac{\mathrm{R}_{\mathrm{sr}}}{\sigma \mathrm{L}_{\mathrm{s}}} \mathrm{i}_{\mathrm{Q}}^{\prime}+\frac{1}{\sigma \mathrm{L}_{\mathrm{s}}} \mathrm{u}_{\mathrm{Q}}^{\prime \prime}
\end{aligned}
$$

The whole scheme of the current controller is reported in Figure 4.

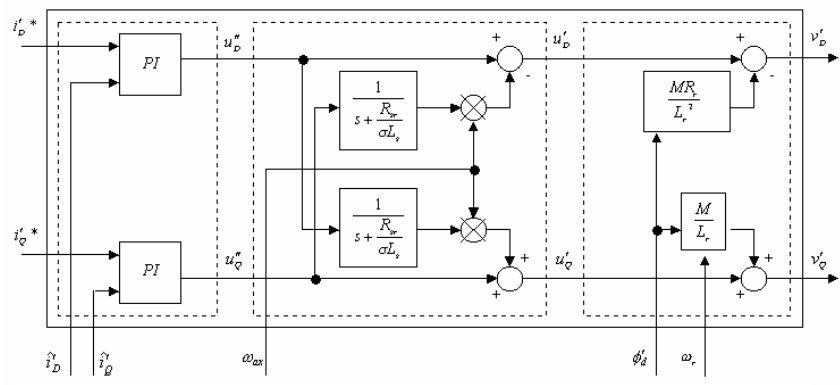

Figure 4: Current controller equivalent scheme.

\section{Simulation results}

The simulation results have concurred to validate the performances of the proposed control strategy. The simulations presented show the worst case operating conditions and confirm the good performance of the control system in the different operating phases of the APU. Figures 5-9 report, respectively, the generated and demanded power, generated and request electric torque, real and reference shaft speed, real and reference average engine torque, and current battery. The calibration of the parameters of the controllers has been executed with the main purpose of obtaining a good tracking of the demanded power and to minimize the oscillations of the current battery.

The simulation starts with a step power request of $7 \mathrm{~kW}$, greater than the maximum power $(6 \mathrm{~kW})$ that is possible to generate at $2000 \mathrm{rpm}$. So, during the first seconds of the simulation, the EM drives the ICE up to $2000 \mathrm{rpm}$ with a maximum speed acceleration equal to $1000 \mathrm{rpm} / \mathrm{s}$. When the shaft speed of $2000 \mathrm{rpm}$ is reached, the engine is switched on and the electric motor starts working as generator furnishing power to charge the battery. In this configuration, the ICE regulates the shaft speed at the desired value, obtained from the power reference. Then the demanded power is increased at $10 \mathrm{~kW}$ and after decreased at $3 \mathrm{~kW}$ which corresponds again to a reference speed equal to $2000 \mathrm{rpm}$. Finally, when the power request is zero, the ICE is switched off and the EM drives the shaft speed to zero with a maximum deceleration equal to $1000 \mathrm{rpm} / \mathrm{s}$.

\section{Conclusions}

In this paper a new APU control strategy for series type hybrid electric vehicles has been proposed. Different 
operating phases of the APU are considered and the corresponding controllers for the internal combustion engine and the electric motor are detailed. A reference signals generator determines the required torque and speed in the different APU phases. During the power generation phases the controller exploits the separation between the slow dynamics of the engine and the fast dynamics of the motor, thus controlling in speed the former and in torque the latter. Simulation results carried out with Matlab/Simulink show the good steady state and dynamic performance of the controlled APU which satisfies the realistic constraints in terms of battery current oscillations due to the engine torque and dynamic transients. The implementation of the proposed APU controller on a real electronic control unit is under development.

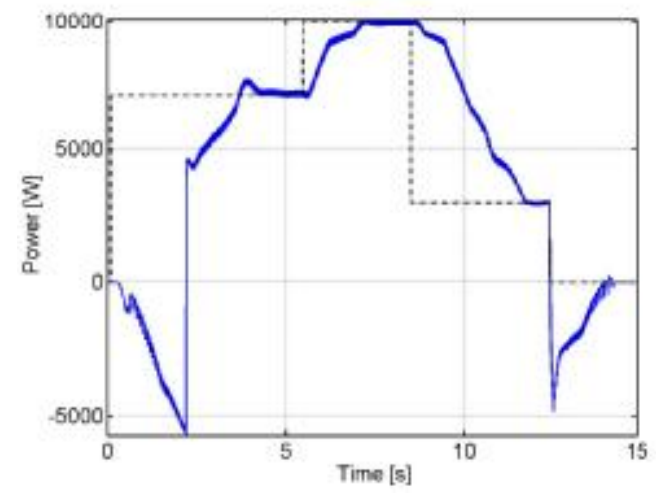

Figure 5: Generated and demanded power.

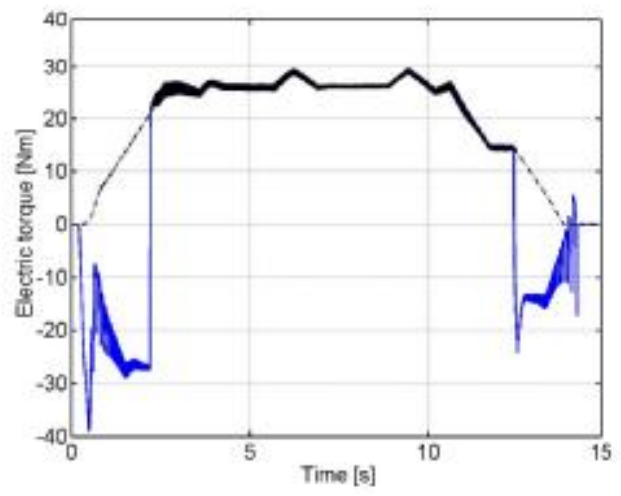

Figure 6: Generated and request electric torque.

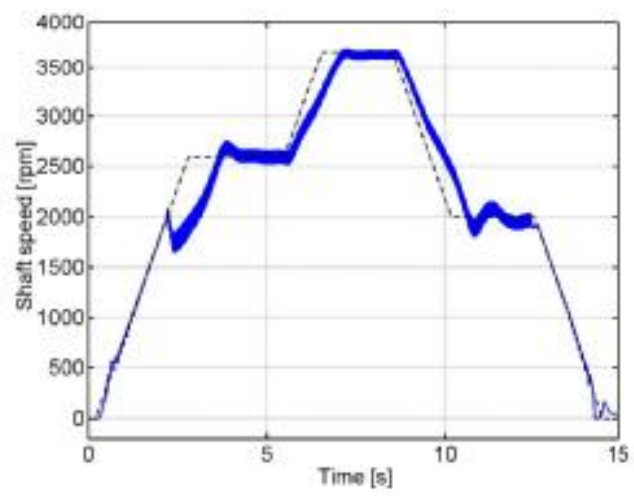

Figure 7: Real and reference shaft speed.

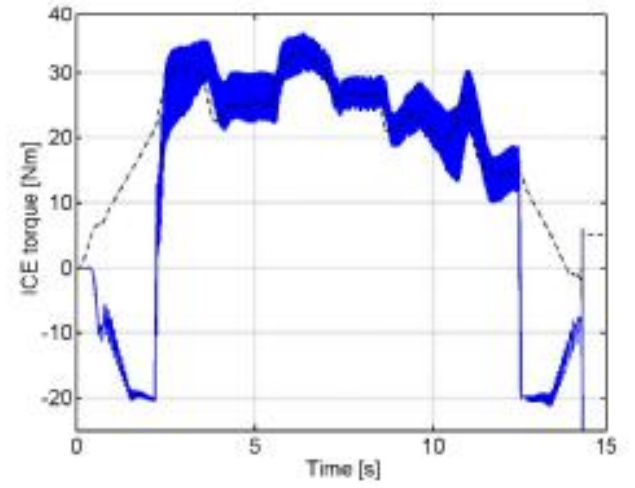

Figure 8: Real and reference average engine torque.
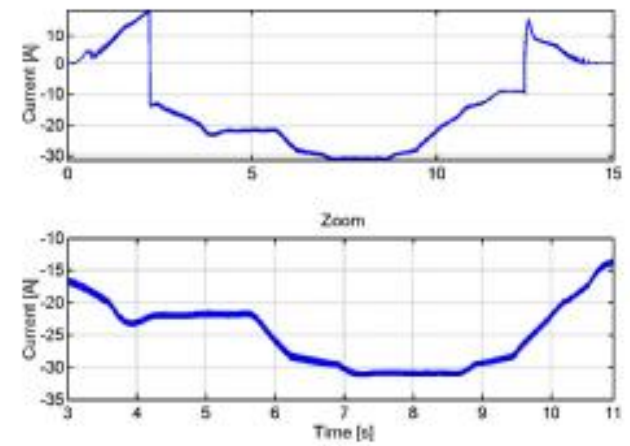

Figure 9: Current battery; the battery has a nominal voltage equal to $312 \mathrm{~V}$ (12 V with 26 cells).

\section{Acknowledgement}

Authors would like to thank Luigi Gortan, Francesco Pastorelli and Immacolata Cascelli from CRF and Luigi Glielmo from University of Sannio for their supervision of the research project and Nicola Testa for his help in producing the simulation results.

\section{References}

[1] G. Barba, L. Glielmo, V. Perna, F. Vasca, "Current Sensorless Induction Motor Observer and Control for Hybrid electric Vehicles", IEEE Power Electronics Specialists Conference, Vancouver, Canada, 2001.

[2] S.C. Chang, S.N. Yeh, "Principles and Practice of Automatic Process Control", John Wiley and Sons, 1997.

[3] CRF Internal report, IR0345.

[4] D. Giacosa, "Motori endotermici", Ulrico Hoepli.

[5] A.R. Guido, L. Della Pietra, "Lezioni di meccanica delle macchine", CUEN.

[6] E. Hendricks, A. Chevalier, M. Jensen, S.C. Serenson "Modelling of the Intake Manifold Filling Dynamics", SAE Technical Paper No. 960037, 1996.

[7] J.B. Heywood, "Internal Combustion Engine Fundamentals", McGraw Hill, 1988.

[8] U. Kiencke, L. Nielsen, "Automotive Control Systems for Engine, Driveline, and Vehicle”, Springer, 2000. 